syndrome in extensive haemangioma of the tongue and lip in a newborn infant. ${ }^{4}$

Thirdly, the substernal goitres reported in the literature have not been uniformly defined in relation to the proportion of the thyroid gland within the thorax. Therefore, it is rather difficult to compare the sizes and the results of reported series of substernal goitres. For the last decade, we and others ${ }^{5}$ have chosen to refer to any goitre in which more than $50 \%$ of its mass is inferior to the thoracic inlet as substernal.

LUC A MICHEL JULIAN DONCKIER Mont-Godinne University (UCL) Hospital, Yvoir, B-5530, Belgium

Accepted 27 July 1998

1 Anders HJ. Compression syndromes caused by substernal goitres. Postgrad Med 7 1998;74:3279.

Michel LA, Bradpiece HA. Surgical management of substernal goitre. $\mathrm{Br} \mathcal{F}$ Surg 1988;75:

3 Gadisseux P, Minette P, Trigaux JP, Michel L. Cerebrovascular circulation 'steal' syndrome secondary to a voluminous retrotracheal goiter. Int Surg 1986;71:107-9.

4 Ismagalov MF. The cerebrovascular circulation 'steal' syndrome in extensive hemangioma of the tongue and lip in a newborn infant. Pediatra 1983;7:64-5.

5 Katlic MR, Grillo HC, Wang CC. Substerna goitre. Ann Thorac Surg 1985;99:391-9.

\section{Anaphylactoid reaction to hydroxycobalamin with tolerance of cyanocobalamin}

Sir,

A patient with an anaphylactoid reaction to hydroxycobalamin but good tolerance of cyanocobalamin is described, which emphasizes the usefulness of challenge tests in cases of allergic or pseudoallergic reactions.

A 33-year-old woman with a history of Crohn's disease developed subacute combined degeneration of the spinal cord due to vitamin B12 deficiency. Replacement therapy with hydroxycobalamin was established at a dose of $10 \mathrm{mg}$ intramuscularly every month with no problems for more than a year Unexpectedly, 2 hours after a dose, the patient developed generalised urticaria and angioedema with involvement of the upper airway. Prick and intradermal tests performed with $5 \mathrm{mg} / \mathrm{ml}$ and $100 \mu \mathrm{g} / \mathrm{ml}$ of hydroxycobalamin, respectively, were negative. Under in-hospital observation the patient was given $2500 \mu \mathrm{g}$ of hydroxycobalamin by the intramuscular route; $20 \mathrm{~min}$ later, she experienced pruritus on her palms, shortly followed by generalised urticaria, prominent lip and palpebral oedema, hoarseness and chest tightness. The patient was treated with epinephrine, methylprednisolone and chlorpheniramine with total recovery in 2 hours. A challenge test with benzyl alcohol, added as preservative, was carried out with no reaction. On the basis that the neurologic manifestations would progress without adequate replacement treatment, a desensitisation protocol was developed. Increasing doses of hydroxycobalamin, beginning with 0.05 $\mu \mathrm{g}$, were administered every $15 \mathrm{~min}$ by the intramuscular route. Ten minutes after the injection of $125 \mu \mathrm{g}$ of hydroxycobalamin, the same allergic reaction appeared. Premedication with antihistamines did not provide reliably effective protection from the hydroxycobalamin-induced reaction in the patient. However, intramuscular challenge tests with cyanocobalamin up to $10 \mathrm{mg}$, performed on three different occasions, were followed by no reaction. At present, the patien receives $10 \mathrm{mg}$ of cyanocobalamin monthly without problems.

Cobalamin is an organometallic vitamin which cannot be synthesized in the human body and must be supplied in the diet. The minimum daily requirement is about $2.5 \mu \mathrm{g}$ In patients with disease of the distal small intestine such as Crohn's disease, cobalamin deficiency may develop. In order to avoid clinical features of cobalamin deficiency, especially neurologic manifestations, replacement therapy is suggested. Because ora absorption is inadequate, replacement must be administered parenterally. The vitamin preparations which are used therapeutically are cyanocobalamin and hydroxycobalamin (both also called vitamin B12) given intramuscularly at monthly periods and maintained indefinitely. Allergic reactions to vitamin $\mathrm{B} 12$ are rare but can be observed even after several years of treatment.' James and Warin reported one patient with dyspnoea and urticaria in the course of a treatment with cyanocobalamin and hydroxycobalamin in which specific IgE could not be showed, suggesting an anaphylactoid reaction rather than a real allergic mechanism. ${ }^{2}$ Recognising that a reaction is caused by direct histamine release may be important since treatment can generally be continued by lowering the dose of the drug. In the patient reported here, the immediate response obtained with low doses of hydroxycobalamin $(125 \mu \mathrm{g})$ on rechallenge, the tolerance of previous doses of this drug (sensitisation period), together with the perfect tolerance of therapeutic doses of cyanocobalamin suggests an allergic mechanism even in the presence of negative skin tests. Even though the reaction developed only at or above a dose of $125 \mu \mathrm{g}$, it is difficult to explain this as an anaphylactoid mechanism, since the capacity of hydroxycobala$\min$ and cyanocobalamin to induce direct release of histamine is quite similar. A reaction to an excipient rather than to the drug itself was ruled out because the only preservative in the formulation was benzyl alcohol (provided by the manufacturer) which was well tolerated by the patient on challenge. Up to now, positive skin tests with hydroxycobalamin have been described in only two patients..$^{3-4}$ Accordingly, cyanocobalamin may be tried as an alternative in patients with a history of systemic reactions to hydroxycobalamin.

C VIDAL Allergy Unit A LORENZO Division of Gastroenterology Hospital de Conxo, Complejo Hospitalario Universitario, Rúa Ramón Baltar sn, 15706 Santiago de Compostela, Spain

Accepted 27 July 1998

1 Ugwu CN, Gibbins FJ. Anaphylactic reaction to vitamin $\mathrm{B} 12$ appearing after several years of treatment. Age Ageing 1981;10:196-7.

2 James J, Warin RP. Sensitivity to cyanocobalamin and hydroxocobalamin. BMF 1971;2:262. 3 De Blay F, Sager MF, Hirth C, et al. IgE-mediated reaction to hydroxocobalamin injection in patient with pernicious anaemia. Lancet 1992;339:1535-6.

4 Branco-Ferreira M, Clode MH, PereiraBarbosa MA, Palma-Carlos AG. Anaphylactic reaction to hydroxycobalamin. Allergy 1997;52: $118-9$.

\section{Salvage angioplasty following failed thrombolysis}

Sir,

Drs Mahy and Jennings are correct to point out the dilemmas facing physicians responsible for the further management of patients with acute myocardial infarction and apparent failure to respond to thrombolytic therapy. ${ }^{1}$ The lack of evidence supporting any particular management strategy is surprising given that up to $50 \%$ of patients fail to respond to thrombolytic therapy in the first few hours and that persistent ST segment elevation following acute myocardial infarction (AMI) is clearly associated with poor outcome. Purcell et al demonstrated mortality of $18.2 \%$ in unselected patients with AMI and $<50 \%$ resolution of ST segment elevation in the worst lead 60 minutes after the initiation of thrombolytic therapy. A substudy ${ }^{3}$ of the INJECT trial revealed a mortality of $17.5 \%$ in patients with $\leqslant 30 \%$ resolution of the summed ST segment elevation in leads reflecting the infarct zone. Even though it is frequently stated that such electrocardiographic (ECG) features are not $100 \%$ sensitive or specific for persistent arterial occlusion, the presence of such features must alert us to a patient who is at high risk of further adverse events. Salvage angioplasty has only been examined in one large prospective randomised study against conservative therapy. ${ }^{4}$ Despite a statistically significant reduction in the incidence of death or severe heart failure, this strategy has not been widely adopted nor examined further in the modern angioplasty era. This is surprising, given that this study probably underestimated the benefit of salvage angioplasty for a number of reasons. Firstly, high-risk patients, including those with a previous myocardial infarction who are perhaps more likely to benefit from attempts to open a second vessel, were excluded. Secondly, patients in this trial were taken on for salvage angioplasty relatively late after the onset of chest pain. Thirdly, intra-aortic balloon counterpulsation was rarely used, but is now known to reduce the risk of arterial occlusion following salvage angioplasty. ${ }^{5}$ Fourthly, the trial was performed without modern glycoprotein IIb/III a inhibitors, such as abciximab (Reopro ${ }^{8}$ ). These agents have been shown to be beneficial in high-risk angioplasty withou increased risk of haemorrhage. ${ }^{6}$ Lastly, and most importantly, this trial was performed in the early 1990s before the modern coronary artery stent era. It is undoubtedly the case that the availability of coronary artery stents allows angioplasty in the context of AMI to be performed with greater success. We would go so far as to say that the results of the trials of immediate angioplasty following thrombolytic therapy, which universally demonstrated unfavourable outcomes with this strategy, have no relevance in the modern stent era This is an area which commands furthe study. Our policy of performing salvage angioplasty in the context of $<50 \%$ ST segment resolution in the worst lead 2 hours after the initiation of thrombolytic therapy has produced favourable results, especially if the patient presents promptly, receives thrombolysis promptly and the 2-hour ECG is scrupulously reviewed. Our experience is that this policy can reduce mortality from an expected $17-20 \%$ to $5 \%$. Thus, patients with persistent ST elevation following thrombolytic therapy should be considered early for 
coronary angiography with a view to salvage angioplasty. Some patients will have reperfused by the time of coronary angiography if the above ECG criteria are applied, but we believe that the potential benefits far outweigh the risks of an 'unnecessary' angiogram.

A G C SUTTON M A DE BELDER

Cardiothoracic Division, South Cleveland Hospital, Marton Road, Middlesbrough TS4 3BW, UK

Accepted 27 July 1998
1 Mahy IR, Jennings JP. 'Rescue' after failed Mahy IR, Jennings JP. 'Rescue' after failed thrombolysis for acute myocard

2 Purcell IF, Newall N, Farrer M. Change in ST segment elevation 60 minutes after thrombolytic initiation predicts clinical outcome as accurately as later changes. Heart 1997;78:465-71.

3 Schroder R, Wegscheider K, Schroder K, Dissman R, Meyer-Sabellek W. Extent of early ST segment elevation resolution: a strong predictor of outcomes in patients with acute myocardial infarction and a sensitive measure to compare thrombolytic regimens. A substudy of the International Joint Efficacy Comparison of Thrombonational Joint Emcacy Comparison of Thrombo. $A C C$ 1995;26:1657-64.

Ellis SG, Ribeiro-da Silva E, Heyndrickx G, et oplasty with conservative management of patients with early failure of thrombolysis for acute anterior myocardial infarction. Circulation 1994; 90:2280-4.

5 Ishihara M, Sato H, Tateishi $\mathrm{H}$, et al. Intraaortic balloon pumping as adjunctive therapy to rescue coronary angioplasty after failed thrombolysis in anterior wall acute myocardial infarction. $A m \mathcal{F}$ Cardiol 1995;76:73-5.

6 The EPILOG Investigators. Platelet glycoprotein IIb/IIIa receptor blockade and low-dose heparin during percutaneous coronary revascularization. N Engl F Med 1997;336:1689-96.

\section{Images in medicine}

\section{Foreign body aspiration}

A 76-year-old woman with known squamous carcinoma of the post-cricoid region, previously treated with laryngopharyngectomy and radiotherapy, was referred to a tertiary hospital having aspirated her Blomsinger tracheo-oesophageal valve (size $10 \mathrm{~mm}$, figure 1). Clinically she had a stridor, and was cyanosed, dyspnoeic and unconscious. Oxygen saturation was $85 \%$ on $60 \%$ inspired oxygen via a Venturi mask. Chest X-ray (figure 2) showed a massive left hydropneumothorax (pneumothorax was created by a previous aspiration) and the Blomsinger valve lodged at the right hilum. Fibre-optic bronchoscopy revealed the valve to be lodged in the right intermediate bronchus. When the valve was removed the patient rapidly improved, with an oxygen saturation of $98 \%$ on $40 \%$ inspired oxygen.

The anatomy of the bronchial tree is such that the right main bronchus is shorter and wider than the left, and it separates off from the vertical at about $25^{\circ}$ compared to the left at $45^{\circ}$. This makes aspiration more common in the right lower and middle lobes.

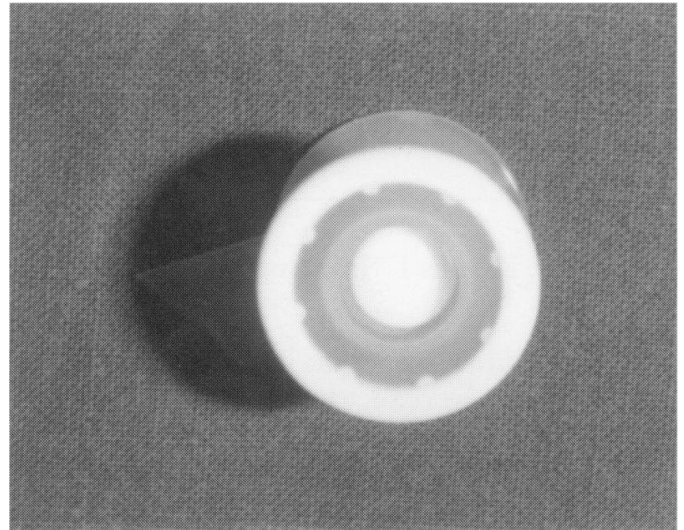

Figure 1 Blomsinger tracheo-oesophageal valve

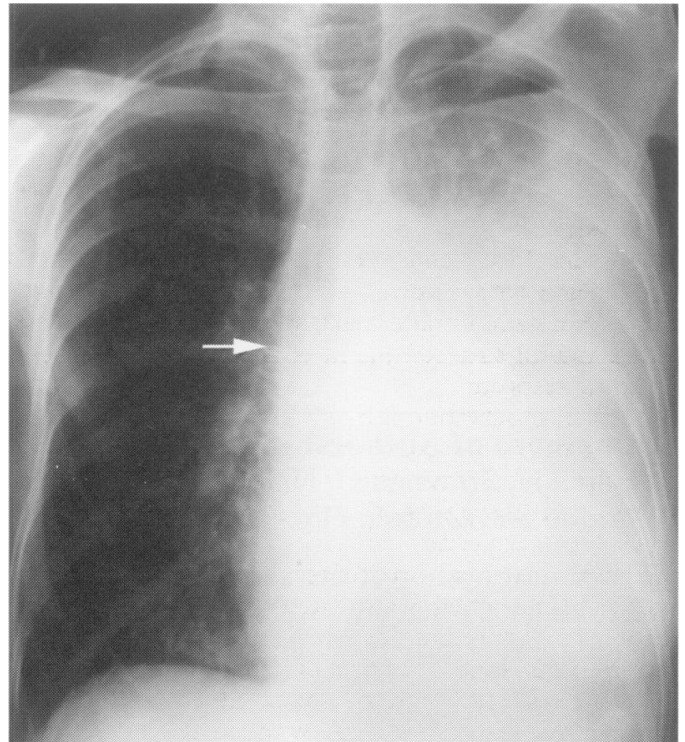

Figure 2 Chest X-ray 